\title{
PERSEPSI MAHASISWA PENDIDIKAN MATEMATIKA TENTANG PELAKSANAAN PRAKTIK PENGALAMAN LAPANGAN (PPL) OLEH FAKULTAS KEGURUAN DAN ILMU PENDIDIKAN UNIVERSITAS PASIR PENGARAIAN
}

\author{
Hera Deswita ${ }^{1}$ \\ Universitas Pasir Pengaraian \\ heraiwit18@gmail.com
}

\begin{abstract}
ABSTRAK Praktik Pengalaman Lapangan (PPL) merupakan salah satu mata kuliah yang bertujuan untuk mempraktikkan teori mengajar dan mempelajari informasi riil yang terjadi di sekolah. Pelaksanaan program ini perlu dievaluasi agar dikemudian hari dapat dilaksanakan lebih baik. Penelitian ini bertujuan untuk mendeskripsikan persepsi mahasiswa matematika tentang pelaksanaan PPL pada tahun akademik 2017/2018. Jenis penelitian ini adalah deskriptif kuantitatif. Data diperoleh melalui penyebaran angket kepada mahasiswa matematika yang telah selesai melaksanakan PPL. Berdasarkan hasil penelitian yang telah dipaparkan dapat disimpulkan bahwa penilaian mahasiswa berbeda-beda tentang pelaksanaan PPL dari berbagai komponen. Sebagian besar mahasiswa merasa siap untuk melaksanakan PPL. Kondisi sarana dan prasarana di sekolah mitra bervariasi: ada yang tersedia dan ada yang yang tidak tersedia. Kinerja Guru pamong dan dosen pembimbing sebagian besar sudah terlaksana dengan baik meskipun terdapat beberapa kinerja yang belum dilaksanakan. Pelaksanaan dan proses evaluasi yang dilakukan guru pamong berjalan dengan baik.
\end{abstract}

Kata-Kata Kunci : Persepsi Mahasiswa, PPL

\section{PENDAHULUAN}

Program studi Pendidikan matematika lahir dari suatu tujuan mulia yaitu untuk menghasilkan tenaga pendidik/ guru matematika yang professional dibidangnya baik dari segi keilmuan matematika maupun penguasaan bidang Pendidikan. Teori yang telah diperoleh oleh mahasiswa selama mengikuti perkuliahan perlu diaplikasikan dalam bentuk praktik pengalaman Lapangan (PPL). Tujuan program PPL adalah untuk mempraktikkan teori mengajar dan mempelajari informasi riil yang terjadi di sekolah. Dalam pelaksanaan PPL adalah beberapa elemen yang berperan penting yaitu unit pelaksana, mahasiswa sebagai guru PPL, sekolah mitra dan dosen pembimbing lapangan. Kerjasama yang baik antar elemen tersebut sangat berpengaruh terhadapa keberhasilan pelaksaan program PPL.

Mahasiswa pendidikan matematika sebagai peserta PPL akan berperan sebagai seorang Pendidik/guru matematika di sekolah mitra. Agar berhasil dalam 
melaksanakan program PPL, mahasiswa harus menguasai keilmuan matematika dan teori Pendidikan. Keterampilan mengajar bagi seorang guru merupakan hal yang sangat penting. Djamarah (2000:99) Menyatakan bahwa arti penting itu bertolak dari tugas dan tanggung jawab seorang guru yang cukup berat untuk mencerdaskan anak didiknya. Kerangka berpikir seperti ini menghendaki seorang guru untuk melengkapi dirinya dengan berbagai keterampilan yang diharapkan dapat membantu dalam menjalankan tugasnya dalam interaksi edukatif. Keterampilan dasar mengajar adalah keterampilan yang mutlak harus dimiliki oleh seorang guru. Asril (2015:68) menjelaskan bahwa para ahli dari Standford University dan Sidney University mengidentifikasi sekitar 22 jenis keterampilan dalam mengajar. Keterampilan-keterampilan tersebut dapat dilompok menjadi delapan keterampilan dasar mengajar (KDM) yaitu keterampilan membuka dan menutup pelajaran, keterampilan menjelaskan, keterampilan bertanya, keterampilan mengadakan variasi, keterampilan memberi penguatan, keterampilan membimbing diskusi, keterampilan mengelola kelas, dan terakhir keterampilan mengajar kelompok kecil dan perorangan. Penguasaan terdapat KDM dapat menjadi indikator keberhasilan guru dalam menciptakan pembelajaran yang bermakna.

Selain itu, ketersediaan sarana dan prasarana juga berpengaruh terhadapat keberhasilan guru dalam membuat siswa untuk belajar pembelajaran dapat berjalan dengan baik jika tersedia sarana dan prasarana yang baik pula. Saran dan prasarana yang dapat menunjang pelasanaan proses belajar diantaranya ruang kelas yang nyaman, ketersedian buku panduan yang relevan, ketersedia jaringan internet/hotspot jika pembelajaran berbasis google classroom, laboratorium dan lokasi sekolah yang terjangkau bagi siswa. Pihak sekolah memiliki kewajiban dalam penyediaan sarana dan prasarana tersebut. Fitriani (2017) menjelaskan bahwa Proses pembelajaran berlangsung dalam suasana tertentu yakni situasi belajar mengajar. Dalam situasi ini, terdapat faktor-faktor yang saling berhubungan yaitu: tujuan pembelajaran, siswa yang belajar, guru yang mengajar, bahan yang diajarkan, metode pembelajaran, alat bantu mengajar, prosedur penilaian, dan situasi pengajaran. Dalam proses pengajaran tersebut, semua faktor bergerak secara dinamis dalam suatu rangkaian yang terarah dalam rangka membawa para siswa/peserta didik untuk mencapai tujuan pengajaran.

Dalam menjalankan peran sebagai seorang pendidik ada beberapa kompetensi yang harus dimiliki oleh guru. Berdasarkan Peraturan Menteri Pendidikan Nasional Republik Indonesia Nomor 16 Tahun 2007 tentang Standar Kualifikasi Akademik dan Kompetensi Guru dikembangkan secara utuh dalam empat kompetensi meliputi kompetensi pedagogik, kompetensi kepribadian, kompetensi sosial dan kompetensi profesional yang diperoleh melalui pendidikan profesi. Dalam proses pembelajaran di kelas, komptensi prosesional sangat berperan besar. Menurut Undang-undang Guru dan Dosen tahun 2005, Kompetensi profesional adalah kemampuan penguasaan materi pelajaran secara mendalam dan luas.

Pada penelitian ini ada beberapa komponen yang dievaluasi dalam pelaksanaan PPL yaitu komponen persiapan, sarana dan prasarana, kinerja pamong, kinerja dosen pembimbing, pelaksanaan, dan kompenen evaluasi (Ismiyanto, 2013) 
Tujuan penelitian ini adalah untuk mendeskripsikan persepsi mahasiswa pendidikan matematika tentang pelaksanaan praktik pengalaman lapangan pada tahun akademik 2017/ 2018.

\section{METODE PENELITIAN}

Jenis penelitian ini merupakan penelitian deskriptif kuantitatif. Sugiyono (2011: 13) menjelaskan bahwa metode kuantitatif adalah penelitian berupa angka-angka dan analisis menggunakan statistik., sedangkan penelitian deskriptif merupakan penelitian yang dilakukan untuk mengetahui nilai variable mandiri, baik satu variable atau lebih (independen) tanpa membuat perbandingan, atau menghubungkan dengan variabel yang lain. Pada penelitian ini akan di deskrisikan persepsi mahasiswa tentang pelaksanaan PPL berdasarkan persentase jawaban angket yang diisi. Subjek pada penelitian ini adalah mahasiswa Pendidikan matematika FKIP UPP yang telah menyelesaikan PPL padaa tahun akademik $2017 / 2018$ sebanyak 25 orang.

Angket yang diberikan kepada responden terdiri dari 6 kompenen dan setiap komponen terdiri dari beberapa pernyataan. Mahasiswa memberikan respon terhadap angket dengan memilih salah satu dari jawaban "ya" atau "tidak". Metode analisis yang digunakan pada penelitian ini adalah deskriptif persentase yang dilakukan menggunakan program Microsoft Excel. Selanjutnya hasil analisis tersebut dideskripsikan berdasarkan perolehan data pada jawaban angket.

\section{HASIL DAN PEMBAHASAN}

A. Komponen Persiapan

Tabel 1. Persepsi Mahasiswa Pendidikan Matematika Terhadap Pelaksanaan PPL Berdasarkan Komponen Persiapan

\begin{tabular}{|c|c|c|c|c|c|}
\hline \multirow{3}{*}{ No } & \multirow{3}{*}{ Pernyataan } & \multicolumn{4}{|c|}{ Jawaban } \\
\hline & & \multicolumn{2}{|c|}{$\mathrm{Ya}$} & \multicolumn{2}{|c|}{ Tidak } \\
\hline & & Angka & $\%$ & Angka & $\%$ \\
\hline 1 & $\begin{array}{l}\text { Anda mengikuti dan memahami } \\
\text { perkuliahan microteaching dengan } \\
\text { baik selama satu semester }\end{array}$ & 25 & 100 & 0 & 0 \\
\hline 2 & $\begin{array}{l}\text { Mahasiswa PPL mendapat pelatihan } \\
\text { dalam membuat perangkat } \\
\text { pembelajaran (Prota, Promes, silabus } \\
\text { dan RPP) }\end{array}$ & 24 & 96 & 1 & 4 \\
\hline 3 & $\begin{array}{l}\text { Mahasiswa PPL mendapat } \\
\text { pembekalan ilmu pedagogik }\end{array}$ & 24 & 96 & 1 & 4 \\
\hline 4 & $\begin{array}{l}\text { Proses Pendaftaran PPL menyulitkan } \\
\text { mahasiswa }\end{array}$ & 5 & 20 & 20 & 80 \\
\hline 5 & $\begin{array}{l}\text { Mahasiswa PPL mengalami kesulitan } \\
\text { dalam mencari lokasi sekolah mitra/ } \\
\text { tempat PPL }\end{array}$ & 5 & 20 & 20 & 80 \\
\hline
\end{tabular}




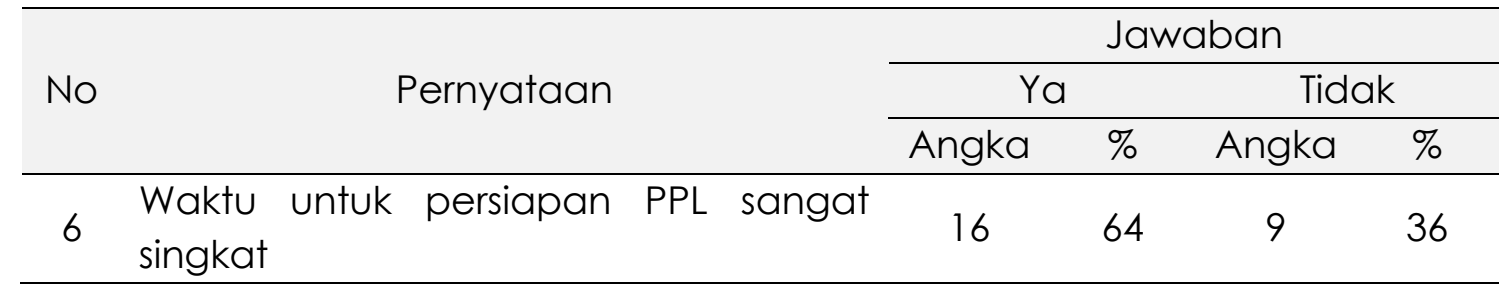

Tabel 1 menunjukkan bahwa persepsi mahasiswa terhadap kesiapan pelaksanaan PPL sudah baik ditinjau dari pemahaman terhadap materi dalam pelaksanaan mengajar maupun proses pendaftaran PPL.

B. Komponen Sarana Dan Prasarana

Tabel 2. Persepsi Mahasiswa Pendidikan Matematika Terhadap Pelaksanaan PPL Berdasarkan Komponen Sarana dan Prasarana

\begin{tabular}{clcccc}
\hline \multirow{2}{*}{ No Pernyataan } & \multicolumn{4}{c}{ Jawaban } \\
\cline { 3 - 6 } & \multicolumn{3}{c}{ Ya } & \multicolumn{3}{c}{ Tidak } \\
\cline { 3 - 6 } 1 & $\begin{array}{l}\text { Sngka } \\
\text { Sekolah mitra memiliki ruang kelas yang }\end{array}$ & 19 & 76 & 6 & 24 \\
\hline $\begin{array}{l}\text { memadai } \\
2\end{array}$ & $\begin{array}{l}\text { Sekolah mitra memiliki media } \\
\text { pembelajaran yang diperlukan oleh } \\
\text { mahasiswa PPL }\end{array}$ & 10 & 40 & 15 & 60 \\
\hline 3 & $\begin{array}{l}\text { Sekolah mitra memiliki buku panduan } \\
\text { pelajaran yang relevan }\end{array}$ & 20 & 80 & 5 & 20 \\
\hline 4 & $\begin{array}{l}\text { Sekolah mitra memiliki jaringan } \\
\text { internet/Hot Spot secara gratis }\end{array}$ & 14 & 56 & 11 & 44 \\
\hline 5 & $\begin{array}{l}\text { Laboratorium IPA di sekolah mitra } \\
\text { memiliki media/ peralatan yang } \\
\text { lengkap }\end{array}$ & 7 & 28 & 18 & 72 \\
\hline 6 & $\begin{array}{l}\text { Sekolah mitra berada di tempat } \\
\text { strategis dan mudah dijangkau }\end{array}$ & 23 & 92 & 2 & 8 \\
\hline
\end{tabular}

Tabel 2 menunjukkan bahwa persepsi mahasiswa terhadap ketersedian saran dan prasarana bervariasi sesuai dengan kondisi sekolah mitra masing-masing. Yang paling menonjol dalam data tersebut adalah belum tersedianya media yang lengkap do labortorium.

C. Komponen Kinerja Guru Pamong

Tabel 3. Persepsi Mahasiswa Pendidikan Matematika Terhadap Pelaksanaan PPL Berdasarkan Komponen Kinerja Guru Pamong

\begin{tabular}{|c|c|c|c|c|c|}
\hline \multirow{3}{*}{ No } & \multirow{3}{*}{ Pernyataan } & \multicolumn{4}{|c|}{ Jawaban } \\
\hline & & \multicolumn{2}{|c|}{ Ya } & \multicolumn{2}{|c|}{ Tidak } \\
\hline & & Angka & $\%$ & Angka & $\%$ \\
\hline 1 & $\begin{array}{l}\text { Guru pamong memberikan bimbingan } \\
\text { kepada mahasiswa PPL sebelum } \\
\text { mengajar }\end{array}$ & 24 & 96 & 1 & 4 \\
\hline
\end{tabular}




\begin{tabular}{|c|c|c|c|c|c|}
\hline \multirow{3}{*}{ No } & \multirow{3}{*}{ Pernyataan } & \multicolumn{4}{|c|}{ Jawaban } \\
\hline & & \multicolumn{2}{|c|}{$\mathrm{Ya}$} & \multicolumn{2}{|c|}{ Tidak } \\
\hline & & Angka & $\%$ & Angka & $\%$ \\
\hline 2 & $\begin{array}{l}\text { Guru pamong melakukan evaluasi } \\
\text { setelah peserta PPL selesai mengajar }\end{array}$ & 18 & 72 & 7 & 28 \\
\hline 3 & $\begin{array}{l}\text { Guru pamong memberikan model } \\
\text { pembelajaran yang baik kepada } \\
\text { mahasiswa saat observasi }\end{array}$ & 16 & 64 & 9 & 36 \\
\hline 4 & $\begin{array}{lll}\text { Guru pamong menguji } & \text { praktik } \\
\text { pembelajaran peserta PPL } & \\
\end{array}$ & 24 & 96 & 1 & 4 \\
\hline 5 & $\begin{array}{l}\text { Guru pamong melakukan variasi } \\
\text { pembelajaran }\end{array}$ & 10 & 40 & 15 & 60 \\
\hline 6 & $\begin{array}{l}\text { Guru pamong jarang berada di sekolah } \\
\text { yang menjadi lokasi PPL }\end{array}$ & 3 & 12 & 22 & 88 \\
\hline 7 & $\begin{array}{l}\text { Guru pamong masih menggunakn } \\
\text { metode pembelajaran yang } \\
\text { sederhana }\end{array}$ & 22 & 88 & 3 & 12 \\
\hline 8 & $\begin{array}{llr}\text { Guru pamong } & \text { sulit diajak } \\
\text { berkomunikasi/ } & \text { mengevaluasi } \\
\text { pembelajaran } & \end{array}$ & 3 & 12 & 22 & 88 \\
\hline 9 & $\begin{array}{l}\text { Guru pamong bersikap pilih kasih/ } \\
\text { subjektif terhadap peserta PPL tertentu }\end{array}$ & 3 & 12 & 22 & 88 \\
\hline 10 & $\begin{array}{l}\text { Guru pamong bersikap objektif } \\
\text { terhadap mahasiswa PPL }\end{array}$ & 24 & 96 & 1 & 4 \\
\hline
\end{tabular}

Berdasarkan data pada Tabel 3, persepsi mahasiswa terhadapa kinerja guru pamong beragam. Namun secara keseluruhan kinerja guru pamong sudah terlaksana dengan baik.

D. Komponen Kinerja Dosen Pembimbing

Tabel 4. Persepsi Mahasiswa Pendidikan Matematika Terhadap Pelaksanaan PPL Berdasarkan Komponen Kinerja Dosen Pembimbing

\begin{tabular}{clcccc}
\hline \multirow{2}{*}{ No Pernyataan } & \multicolumn{4}{c}{ Jawaban } \\
\cline { 3 - 6 } & \multicolumn{3}{c}{ Ya } & \multicolumn{3}{c}{ Tidak } \\
\cline { 2 - 6 } & Angka & $\%$ & Angka & $\%$ \\
\hline 1 & $\begin{array}{l}\text { Dosen pembimbing menyampaikan } \\
\text { gambaran teknis tentang kegiatan PPL }\end{array}$ & 24 & 96 & 1 & 4 \\
\hline 2 & $\begin{array}{l}\text { Dosen membimbing mahasiswa } \\
\text { menyusun program kerja PPL }\end{array}$ & 13 & 52 & 12 & 48 \\
\hline 3 & $\begin{array}{l}\text { Dosen pembimbing jarang memantau } \\
\text { kegiatan PPL di sekolah mitra }\end{array}$ & 17 & 68 & 8 & 32 \\
\hline 4 & $\begin{array}{l}\text { Dosen Pembimbing mengevaluasi } \\
\text { kegiatan 24ersama mahasiswa PPL }\end{array}$ & 18 & 72 & 7 & 28 \\
\hline
\end{tabular}




\begin{tabular}{clccccc}
\hline \multirow{2}{*}{ No Pernyataan } & \multicolumn{5}{c}{ Jawaban } \\
\cline { 3 - 7 } & \multicolumn{3}{c}{ Ya } & \multicolumn{3}{c}{ Tidak } \\
\cline { 3 - 7 } & Angka & $\%$ & Angka & $\%$ \\
\hline 5 & $\begin{array}{l}\text { Dosen pembimbing setidaknya dating } \\
\text { memantau, sharing dengan mahasiswa } \\
\text { PPL minimal 2 kali dalam seminggu }\end{array}$ & 4 & 16 & 21 & 84 \\
\hline 6 & $\begin{array}{l}\text { Dosen pembimbing sulit ditemui jika } \\
\text { akan konsultasi }\end{array}$ & 3 & 12 & 22 & 88 \\
\hline $\begin{array}{l}\text { Dosen pembimbing jarang } \\
\text { memberikan solusi } \\
\text { permasalahan yang derhadap } \\
\text { mahasiswa PPL di sekolah }\end{array}$ & 1 & 4 & 24 & 96 \\
\hline 8 & $\begin{array}{l}\text { Dosen tidak membimbing dalam } \\
\text { penyusunan laporan akhir }\end{array}$ & 10 & 40 & 15 & 60 \\
\hline 9 & $\begin{array}{l}\text { Dosen membimbing mahasiswa dalam } \\
\text { pembuata RPP }\end{array}$ & 9 & 36 & 16 & 64 \\
\hline
\end{tabular}

Data pada Tabel 4 menunjukkan bahwa terdapat persepsi yang beragam tentang penilaian mahasiswa terhadap kinerja dosen pembimbing. Ada empat pernyataan yang menunjukkan bahwa kinerja dosen pembimbing sudah dilaksanaakan dengan baik yaitu pernyataan 1, 4, 6 dan 7. Sedangkan persepsi mahasiswa terhadap kinerja lainnya berimbang tergantung kondisi dosen pembimbing masing-masing.

E. Komponen Pelaksanaan

Tabel 5. Persepsi Mahasiswa Pendidikan Matematika Terhadap Pelaksanaan PPL Berdasarkan Komponen Pelaksanaan

\begin{tabular}{clcccc}
\hline \multirow{2}{*}{ No Pernyataan } & \multicolumn{4}{c}{ Jawaban } \\
\cline { 3 - 6 } & \multicolumn{3}{c}{ Ya } & \multicolumn{3}{c}{ Tidak } \\
\cline { 3 - 6 } 1 & $\begin{array}{l}\text { Kegiatan PPL dilaksanakan sesuai } \\
\text { dengan jadwal yang telah ditentukan }\end{array}$ & 25 & 100 & 0 & 0 \\
\hline $\begin{array}{l}\text { Kegiatan PPL diawali dengan } \\
\text { perkenalan terhadap } \\
\text { guru/pegawai dan siswa di sekolah } \\
\text { mitra }\end{array}$ & $\begin{array}{c}\text { Angluruh } \\
\text { sung }\end{array}$ & 25 & 100 & 0 & 0 \\
\hline 3 & $\begin{array}{l}\text { Monitoring yang dilakukan oleh UPPL di } \\
\text { sekolah mitra PPL kurang berjalan }\end{array}$ & 16 & 64 & 9 & 36 \\
\hline 4 & $\begin{array}{l}\text { Ada kendala dalam penarikan } \\
\text { mahasiswa PPL dari sekolah mitra }\end{array}$ & 1 & 4 & 24 & 96 \\
\hline 5 & $\begin{array}{l}\text { Mahasiswa PPL wajib masuk setiap hari } \\
\text { ke sekolah mitra }\end{array}$ & 16 & 64 & 9 & 36 \\
\hline 6 & $\begin{array}{l}\text { Mahasiswa PPL diperbolehkan izin } \\
\text { sewaktu/waktu }\end{array}$ & 24 & 96 & 1 & 4 \\
\hline
\end{tabular}




\begin{tabular}{clllll}
\hline \multirow{2}{*}{ No } & & \multicolumn{3}{c}{ Jawaban } \\
\cline { 3 - 6 } & \multicolumn{3}{c}{ Ya } & \multicolumn{2}{c}{ Tidak } \\
\cline { 2 - 6 } & Angka & $\%$ & Angka & $\%$ \\
\hline 7 & $\begin{array}{l}\text { Mahasiswa PPL diharuskan memberikan } \\
\text { kenang-kenangan sesuai permintaan } \\
\text { sekolah mitra pada akhir kegiatan }\end{array}$ & 2 & 8 & 23 & 92 \\
\hline $\begin{array}{l}\text { Mahasiswa PPL memberi kenang- } \\
\text { kenangan ke sekolah mitra pada akhir } \\
\text { kegiatan, }\end{array}$ & 24 & 96 & 1 & 4 \\
\hline
\end{tabular}

Berdasarkan data yang disajikan pada Tabel 5 di atas, pelaksanaan PPL sudah berjalan dengan baik. Pelaksanaan PPL baik oleh pihak unit pelaksana, pihak sekolah dan kegiatan dalam PPL dinilai baik oleh mahasiswa.

F. Komponen Evaluasi

Tabel 6. Persepsi Mahasiswa Pendidikan Matematika Terhadap Pelaksanaan PPL Berdasarkan Komponen Evaluasi

\begin{tabular}{|c|c|c|c|c|c|}
\hline \multirow{3}{*}{ No } & \multirow{3}{*}{ Pernyataan } & \multicolumn{4}{|c|}{ Jawaban } \\
\hline & & \multicolumn{2}{|c|}{ Ya } & \multicolumn{2}{|c|}{ Tidak } \\
\hline & & Angka & $\%$ & Angka & $\%$ \\
\hline 1 & $\begin{array}{l}\text { Mahasiswa PPL melaksanakan ujian } \\
\text { sesuai jadwal yang ditentukan guru } \\
\text { pamong masing-masing }\end{array}$ & 22 & 88 & 3 & 12 \\
\hline 2 & $\begin{array}{l}\text { Mahasiswa PPL tidak perlu mengikuti } \\
\text { ujian PPL }\end{array}$ & 1 & 4 & 24 & 96 \\
\hline 3 & $\begin{array}{l}\text { Mahasiswa PPL sangat mudah } \\
\text { memahami format laporan PPL }\end{array}$ & 18 & 72 & 7 & 28 \\
\hline 4 & $\begin{array}{l}\text { Pengumpulan laporan hasil PPL } \\
\text { dilakukan secara individu }\end{array}$ & 19 & 76 & 6 & 24 \\
\hline
\end{tabular}

Data pada Tabel 6 menunjukkan bahwa proses evaluasi PPL sudah dilaksanakan dengan baik. kegiatan ujian PPLmahasiswa dilaksnakan sesuai dengan jadwal yang ditentukan dan semua mahasiswa harus mengikuti ujian. Format penilaian dapat dipahami oleh mahasiswa dan pengumpulan laporan hasil PPL dilakukan secara individu

\section{KESIMPULAN DAN SARAN}

Berdasarkan hasil penelitian yang telah dipaparkan dapat disimpulkan bahwa penilaian mahasiswa berbeda-beda tentang pelaksanaan PPL dari berbagai komponen. Sebagian besar mahasiswa merasa siap untuk melaksanakan PPL. Kondisi sarana dan prasarana di sekolah mitra bervariasi: ada yang tersedia dan ada yang yang tidak tersedia. Kinerja Guru pamong dan dosen pembimbing sebagian besar sudah terlaksana dengan baik meskipun terdapat beberapa kinerja yang belum dilaksanakan. Pelaksanaan dan proses evaluasi yang dilakukan guru pamong berjalan dengan baik. 


\section{${ }^{A} \mathrm{BSIS}$}

Untuk memperbaiki pelaksanakan PPL dikemudian hari disarankan kepada unit pelaksana agar lebih memonitoring pelaksanaan PPL baik terhadap kesiapan mahasiswa, sarana-prasarana sekolah mitra, kinerja guru pamong maupun dosen pembimbing agar pelaksanann PPL yang dilakukan dapat berjalan dengan baik.

\section{DAFTAR PUSTAKA}

Asril, Zainal. 2015. MicroTeaching. Jakarta: Raja Grafindo Persada.

Djamarah, Syaiful Bahri. 2000. Psikologi Belajar. Rineka Cipta. Jakarta.

Fitriani, Cut, Murniati AR, Nasir Usman. 2017. "Kompetensi Profesional Guru Dalam Pengelolaan Pembelajaran Di Mts Muhammadiyah Banda Aceh". Jurnal Magister Administrasi Pendidikan Pascasarjana Universitas Syiah Kuala. Volume 5, No. 2, Mei 2017.

Ismiyanto. 2013. "Persepsi Mahasiswa Biologi Tentang Pelaksanaan Program Pengalaman Lapangan (PPL) Oleh Fakultas Keguruan Dan Ilmu Pendidikan UMS Tahun Akademik 2012/2013". Skripsi. UMS

Janawi. 2012. Kompetensi Guru: Citra Guru Professional. Alfabeta, Bandung.

Kemendiknas. 2007. Peraturan Menteri Pendidikan Nasional Republik Indonesia Nomor 16 Tahun 2007.

Sugiyono. 2011. Metode Penelitian Pendidikan Pendekatan Kuantitatif, Kualitatif, dan R\&D. Bandung: Alfabeta. 